\title{
Inner dan Outer Space dalam Kontroversi "Salib" pada Ornamen 75 Tahun Kemerdekaan
}

\author{
Dien Yudithadewi \\ Program Studi Ilmu Komunikasi, Universitas Paramadina Jakarta, Mampang, Jakarta \\ Selatan, Jakarta, Indonesia, \\ yudithasuwarno@gmail.com
}

\section{Bonifasius Parikesit}

Program Studi Ilmu Komunikasi, Universitas Paramadina, Jakarta, Mampang, Jakarta Selatan, Jakarta, Indonesia bonifasius.parikesit@gmail.com

\section{Article Info}

\section{Article History}

Received 31 Aug 2020

Revised 11 Oct 2020

Accepted 20 Oct 2020

\begin{abstract}
This paper focuses on finding out what meaning is reflected in the phenomenon of rejection of ornamental design of the 75th Anniversary of Indonesia's Independence, from the perspective of Yuri Lotman's (Tartu-Moscow-Semiotic School) cultural semiotics. This ornament has become a polemic in society, because a group of people feels that there is a visual cross in it, which is a representation of a certain group. The research finding states that rejection of the ornamental design for the 75th anniversary of the Republic of Indonesia occurred because a group of people felt that the "sign" in the design represented a certain group, outside them. This opinion is described by Yuri Lotman as the concept of "the inner space" (we/us) and "the outer space" (them). According to him, each culture has boundaries for defining itself (Semenenko, 2012). Everything outside "us" is "not our culture" (non-culture) or "foreign" (alien), and is often considered not good because it is not "like us" (Lorusso, 2015)
\end{abstract}

Keywords: yuri lotman's (Tartu-Moscow Semiotic School) cultural semiotics, nationalism, plurality

\begin{abstract}
Abstrak. Tulisan ini berfokus pada upaya mengetahui makna apa yang tercermin dalam fenomena penolakan desain ornamen 75 Tahun Kemerdekaan Indonesia, melalui sudut pandang semiotika budaya Yuri Lotman (Tartu-Moscow-Semiotic School). Ornamen tersebut telah menjadi polemik di masyarakat, akibat sekelompok orang merasa bahwa terdapat visual salib di dalamnya, yang merupakan representasi dari golongan tertentu. Temuan penelitian menyatakan bahwa penolakan desain ornamen 75 tahun kemerdekaan Republik Indonesia terjadi karena sekelompok orang merasa bahwa "tanda" yang ada pada desain tersebut merupakan representasi kelompok tertentu, di luar mereka. Pandangan seperti ini digambarkan oleh Yuri Lotman sebagai konsep "the inner space" (kami/kita) dan "the outer space" (mereka). Menurutnya, tiap kebudayaan mempunyai batasan untuk mendefinisikan diri (Semenenko, 2012). Semua hal di luar "kita" merupakan "bukan budaya kita" (nonculture) atau "asing" (alien), dan acapkali dianggap jelek karena tidak "seperti kita” (Lorusso, 2015).
\end{abstract}

Kata Kunci: semiotika budaya yuri lotman (Tartu-Moscow Semiotic School), nasionalisme, kemajemukan 


\section{PENDAHULUAN}

Salib, merunut akar sejarahnya, telah digunakan sebagai simbol agama tertentu bahkan sebelum era kekristenan dimulai. Sejumlah penelitian menyebut penganut Politeisme atau ajaran Paganisme telah menggunakannya di abad ketujuh (Sari, 2018). Pada masa ini, salib memiliki beberapa corak, salah satunya terdapat dalam hieroglif Mesir kuna. Di situ, salib hadir sebagai simbol, yang merupakan bagian dari sistem tulismenulis. Simbol salib inilah yang kelak diadopsi, lalu digunakan penganut Kristen Koptik di Mesir dan beberapa negara Afrika (Britannica.com, 2018).

Simbol salib sebagai bagian dari identitas kekristenan baru muncul beberapa abad setelah Konstantine mendalami ajaran tersebut. Pada periode ini, salib menjadi lambang kemenangan Kristus atas kuasa kejahatan dan kematian (Selvam, 2017). Namun, alam tulisannya yang berjudul "Muslim Views of the Cross as a Symbol of the Christian Faith" menyebutkan bahwa simbol salib seperti itu tidak dapat diterima oleh penganut agama lain karena dipandang sebagai ritual penyembahan berhala.

Dalam konteks Indonesia, agama Kristen kerap dipandang sebagai agama kaum penjajah. Sebagaimana yang terjadi pada perang salib di daratan Eropa- Afrika, di zaman kolonialisme, Kristen berada pada kubu yang berseberangan dengan Islam yang telah lebih dulu ada di Nusantara. Kondisi dan memori inilah yang kemudian menghantui umat Islam sampai saat ini karena diwartakan demikian oleh para penyebarnya (Prijanto, 2017).

Bentuk salib menjadi sesuatu yang sering diperdebatkan di Indonesia ketika wujud tersebut bermunculan di ruang publik. Ini dapat dirujuk ke dalam beberapa peristiwa yang terjadi belakangan seperti: (1) pemotongan nisan umat Kristiani di Paroki Pringgolayan, Yogyakarta yang disusul dengan perusakan 21 nisan umat Kristiani dan Muslim di tiga tempat pemakaman umum pada 2018; (2) gerakan penolakan ornamen di koridor depan balai kota Surakarta yang terjadi pada 2019 akibat desainnya yang ditengarai menyerupai salib, dan (3) gerakan penolakan desain ornamen peringatan 75 tahun kemerdekaan Republik Indonesia (Gambar 1) lantaran diduga terdapat simbol salib di dalamnya (Gatra.com, 2020)

Ketiga peristiwa yang terjadi dalam tahun yang berurutan menggambarkan realitas intoleransi simbolik yang semakin memprihatinkan (Kompas, 2019). Berangkat dari hal tersebut, utamanya terkait penolakan desain ornamen 75 Tahun Kemerdekaan Indonesia, peneliti bermaksud menelaah makna yang tercermin dari intoleransi simbolik yang terjadi.

Penelitian ini dilakukan melalui pendekatan semiotika budaya Yuri Lotman (Tartu-Moscow-Semiotic School) yang memberi perspektif luas dalam menelaah teks karena bersifat "textocentrist". Bagi Lotman, definisi teks lebih luas dari sekadar literatur, melainkan mencakup budaya, yaitu representasi pikiran (Semenenko, 2012).

Secara lebih mendalam, penelitian ini mengambil rujukan yang berasal dari tulisan berjudul Nation Branding in Romania After 1989: A Cultural Semiotic Perspective. Dalam penelitian tersebut, Cheregi (2017) menganalisis empat kampanye Pemerintah Rumania (pascakomunis) melalui semiotika budaya versi Yuri Lotman (Tartu-Moscow-Semiotic School). Ia berfokus pada analisis iklan dan wacana identitas nasional, juga membahas 
cara unsur-unsur ideologi neoliberal diangkat dalam kampanye pemerintah. Hasil penelitian menyatakan bahwa empat kampanye tersebut mempunyai empat semiosfer berbeda. Kampanye memadukan praktik diskursif diplomasi publik dan periklanan untuk menyampaikan citra nasional kepada audiens, baik internal (warga negara), maupun eksternal (internasional).

Penelitian ini akan mengkaji makna di balik penolakan ornamen 75 Tahun Kemerdekaan RI. Kajian ini penting bukan saja bahwa isu agama dan simbol yang mengiringinya selalu kontroversial, tetapi juga studi semiotika dengan pendekatan Lotman masih jarang dilakukan. Banyak penelitian semiotika biasanya menggunakan model-model analisis Roland Barthes, Pierce, Umberto Eco, dan beberapa model lainnya terutama dari tradisi Eropa Barat. Sebaliknya, kajiankajian semiotika dengan menggunakan pendekatan Tartu-Moscow-Semiotic School belum banyak dilakukan. Oleh karena itu, studi ini diharapkan akan memberikan kontribusi bagi studi semiotika di Indonesia, dan terutama dalam rangka memperluas kajian semiotika dengan menggunakan tradisi Tartu-Moscow-Semiotic School seperti gagasan Lotman.

\section{METODE}

Lotman dan Mazhab TartuMoscow-Semiotic School mendefinisikan semiotika sebagai studi tentang sistem dan proses tanda (Kull, 2015; Lotman, 1990), di mana pendekatannya terhadap budaya bersifat holistik (Torop, 2005). Mazhab ini memandang budaya sebagai teks yang sangat kompleks, sebuah representasi pikiran (Semenenko, 2012) di mana kode kait-mengait, membentuk hubungan dan struktur baru. Lebih lanjut, dikatakan bahwa analisis teks adalah bagian dari identifikasi dan transmisi proses budaya (Kull, 2015; Novikova \& Chumakova, 2015; Semenenko, 2012). Semiotika Lotman melakukan analisis teks dengan menghubungkannya dengan konteks budaya yang lebih luas (Lorusso, 2015; Nazaruddin, 2019).

Poin utama dari pendekatan semiotika Lotman terletak pada semiosfer, sebuah konsep yang diilhami dari biosfer atau semesta makhluk hidup (Cheregi, 2017; Kull, 2015; Lorusso, 2015; Lotman, 2005; Nöth, 2014; Novikova \& Chumakova, 2015; Torop, 2005). Konsep tersebut menggunakan model spasial (semesta) berbatas, dalam interpretasi budaya (Nöth, 2006, 2014).

Semiosfer bisa diibaratkan jaringan memori individu. Bila ingatan individu berada dalam pikiran, ingatan kolektif bersandar pada teks. Dengan demikian, tiap semiosfer berada di dalam semiosfer lain; dimulai dari yang terkecil, yaitu individu, lalu keluarga, kemudian masyarakat, dan seterusnya. Semenenko (2012) mengumpamakan semiosfer seperti boneka mainan khas Rusia, matryoshka. Matryoshka adalah sebuah boneka yang (umumnya) terbuat dari kayu, dimana dalam satu set boneka, terdapat beberapa ukuran. Boneka dengan ukuran yang lebih kecil, terletak di dalam boneka yang lebih besar, lalu keduanya diletakkan dalam boneka yang lebih besar lagi. Misalnya, terdapat tiga ukuran, boneka terkecil berada di dalam boneka berukuran sedang, dan keduanya berada dalam boneka terbesar. Maka, budaya, tanda, dan teks berada dalam budaya, tanda, dan teks lainnya (Cheregi, 2017).

Hal yang krusial dalam semiosfer ialah batas (boundary) yang berfungsi sebagai mekanisme penerjemahan, kontrol, filter, dan katalisator komunikasi (Lotman, 2005; Semenenko, 2012). Proses penerjemahan pesan diutarakan Lotman 
sebagai berikut.

"Because the semiotic space is transected by numerous boundaries, each message that moves across it must be many times translated and transformed, and the process of generating new information thereby snowballs" (Lotman, 1990).

Lebih lanjut, Lotman menguraikan bahwa dalam sebuah sistem budaya, batas menimbulkan dua ruang, yakni inner space dan outer space. Inner space bermakna "kami", sedangkan outer space "mereka", dimana yang tidak sesuai dengan "kami" berarti buruk/salah (Semenenko, 2012). Ini dapat mengambil contoh-contoh seperti terminologi "orang barbar” yang muncul pada masa Yunani kuna untuk menggambarkan bangsa yang tidak beradab/berbudaya. Sesungguhnya, diksi tersebut timbul karena orang Yunani Kuno tidak memahami bahasa yang digunakan oleh bangsa lain, dan terdengar seperti "bar-bar". Bagi masyarakat Yunani kuno, bangsa yang tidak punya bahasa (dalam arti tidak berbicara dengan bahasa yang sama dengan mereka), adalah bangsa yang tidak beradab/berbudaya.

Sejalan dengan itu, Lotman juga berpendapat bahwa secara umum, sebuah sistem budaya memiliki pusat (core), dan pinggiran (periphery). Bagi Lotman, sesuatu yang berada di pusat, sifatnya lebih netral/normal (common to all), sedangkan di pinggiran lebih dinamis dan "brightly coloured and marked" (Lotman, 1990). Suatu hal yang mulanya berada di pusat, bisa berpindah ke pinggiran, dan sebaliknya.

Pengejawantahan konsep pusat dan pinggiran ini bisa dilihat dalam sebuah kota yang memiliki alun-alun sebagai pusat kota, di mana semua bangunan penting yang menyangkut kepentingan publik berada di area tersebut. Sebaliknya, semakin jauh dari pusat kota, fungsi area tidak lagi sepenting pusat, biasanya lebih banyak hunian. Mengenai perpindahan suatu hal dari pusat ke pinggiran, atau sebaliknya, tampak pada tren mode. Celana jin/Denim yang awal kemunculannya hanya ditujukan untuk baju kerja para pekerja kasar di abad 19 (pinggiran), lalu perlahan mulai dikenakan anak muda, kemudian di abad 20 menjadi pakaian "semua orang" (pusat).

Tulisan ini akan menggunakan semiosfer terkecil yang melingkupi kontroversi Salib dalam ornamen 75 Tahun Kemerdekaan Republik Indonesia. Peneliti akan menelaah kasus dengan cara mengupas apa yang terjadi antara inner dan outer space.

\section{HASIL DAN PEMBAHASAN}

Indonesia merupakan negara yang terdiri dari berbagai macam suku, agama, ras dan golongan. Untuk menjaga kesatuan tanpa menghilangkan kemajemukan, para pendiri dan penerus bangsa telah berkomitmen melalui semboyan Bhinneka Tunggal Ika. Artinya, meski berbeda, tapi tetap satu.

Berangkat dari realitas tersebut, semiosfer Indonesia sebagai bangsa mengandung banyak sekali semiosfer kecil di dalamnya. Penelitian ini berfokus pada semiosfer agama, dimana sesuai dengan Keputusan Presiden No 6 tahun 2000 tentang Pencabutan Instruksi Presiden No 14 tahun 1967, negara menjamin kebebasan warganya untuk menganut agama, kepercayaan dan adat istiadat resmi.

Terdapat enam agama dan kepercayaan yang diakui oleh Pemerintah Indonesia dengan Islam berposisi sebagai mayoritas. Maka, dalam semiosfer agama dan kepercayaan di Indonesia, yang berada di pusat (core) adalah Islam, sedangkan 
pinggiran (periphery) dipenuhi oleh lainnya. Berkaitan dengan intoleransi simbolik desain 75 tahun Kemerdekaan RI, (Gambar 2) "kami" (inner space) adalah kelompok penolak, sedangkan "mereka" (outer space), adalah semua kelompok yang tidak sejalan dengan penolakan tersebut.

Kelompok penolak terdiri dari orang-orang yang melakukan penolakan secara langsung, maupun yang mengutarakan pendapat yang cenderung menyetujui pandangan mereka. Sesungguhnya, penolakan yang "resmi", hanya terjadi di Solo, di mana Dewan Syariah Kota Surakarta (DSKS) mendesak pemerintah untuk memperbaiki ornamen tersebut karena dianggap "mencederai perayaan kemerdekaan RI yang seharusnya menjadi momen persatuan bangsa”. Ormas tersebut mengirim surat protes kepada Pemerintah Kota Solo, Gubernur Jawa Tengah, Kementerian Sekretariat Negara, dan Presiden Joko Widodo (CNNIndonesia, 2020a).

Selanjutnya, isu ini bergerak bagai bola salju, dan memunculkan keriuhan pendapat tokoh masyarakat, khususnya di media sosial. Di Sumatera Selatan, mulai dari Ketua GNPF Ulama OKU, Pengurus PA 212 OKU, anggota PERSIS OKU tokoh masyarakat dan pemuda Baturaja, hingga mantan caleg angkat bicara. Mereka menyuarakan pendapat senada, yang intinya kontra terhadap ornamen tersebut. Bahkan, seorang pengurus MUI Baturaja Timur menganggap hal ini sebagai "penggiringan ke arah komunis secara halus" (Liputansumsel.com, 2020).

Pada tingkat nasional, tokoh tertentu mendapat "serangan balik" secara siber, yang kemudian memunculkan pendapat lain yang makin panas. Salah satunya adalah suara Abdullah Gymnastiar atau yang lebih dikenal dengan nama Aa Gym, yang menyatakan bahwa opini yang kontra adalah wajar, dan bisa dimaklumi. Sebagai akibatnya, Aa Gym menuai kecaman masif dari warganet. Hal ini menimbulkan reaksi dari Wakil Sekretariat Jenderal Majelis Ulama Indonesia (MUI), Tengku Zulkarnain atau biasa dipanggil Tengku Zul. Menurutnya, serangan siber terhadap Aa Gym justru membuatnya yakin bahwa ornamen tersebut adalah tanda salib. Bahkan, ia berpendapat: umat mayoritas mau 'digilas' (Gunadha \& Bhayangkara, 2020)

Di dunia maya, terutama pada platform media sosial Twitter, isu ini berkembang menjadi adu argumen yang mengarah pada olok-olokan, dari kubu "outer space". Salah satunya pendapat yang dicuitkan oleh politikus Partai Solidaritas Indonesia, Guntur Romli. Berikut adalah isi twit-nya:

“Apakah mereka yang protes dan nuduh logo kemerdekaan juga akan protes dan haramkan layang-layang karena dilihat seperti salib? Kalau mereka diikuti, masyarakat ini akan ikutan sakit” (Minggu, 9 Agustus 2020, dikutip dari Nariyati, 2020).

Mantan Menteri Agama, Lukman Hakim Saifuddin, turut merespon Aa Gym melalui akun twitter-nya sebagai berikut.

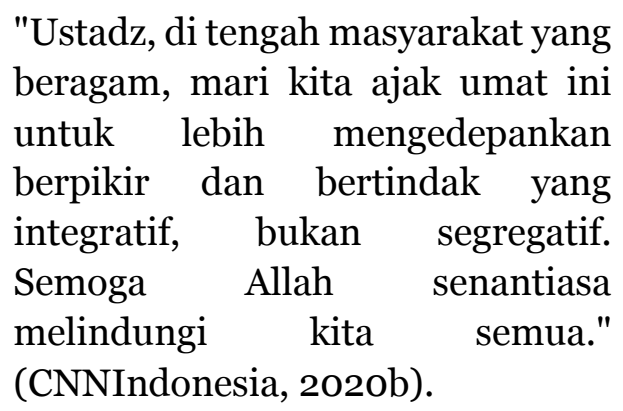

Dengan makin memanasnya situasi, Pemerintah Daerah Karanganyar dan Ogan Komering Ulu memutuskan untuk tidak menggunakan ornamen tersebut ke dalam materi-materi perayaan kemerdekaan. 
Kondisi ini tidak dapat dilepaskan dari dinamika lanskap politik yang menyelimuti republik dalam empat tahun terakhir. Peristiwa tersebut dapat terlihat dari kontestasi Pemilihan Kepala Daerah DKI Jakarta 2017 hingga Pemilihan Presiden 2019.

Periode kampanye Pilkada DKI Jakarta ditandai dengan menggemanya kasus "Al-Maidah" yang melibatkan Petahana sekaligus salah satu bakal calon Gubernur, Basuki Tjahaja Purnama. Penggunaan petikan Al Quran Surat AlMaidah dalam salah satu pidatonya di Kepulauan Seribu menjadi bumerang yang menyudutkan Basuki. Dalam proses yang berlangsung saat itu, Basuki harus menempuh proses pengadilan sebelum kemudian divonis bersalah selama dua tahun dalam kasus penistaan agama (Sugiharto, 2017). Sejak itu, identitas agama menjadi salah satu kartu yang kerap digunakan untuk mendulang suara. Situasi politik yang demikian juga berkembang semakin memanas, dan berlanjut di masa Pemilihan Presiden 2019, bahkan sampai mencuatnya kasus penolakan ornamen logo Kemerdekan RI pada 2020.

Agaknya, kondisi ini terjadi akibat adanya resistensi sekelompok kecil masyarakat terhadap simbol-simbol liyan. Ini juga menjadi tanda menguatnya sikap intoleransi. Padahal, apabila dilihat secara mendalam kontroversi mengenai ornamen hari ulang tahun Republik Indonesia, bukanlah merupakan hal yang benar-benar baru. Perbincangan publik yang melahirkan kontroversi telah terjadi beberapa kali sepanjang Republik Indonesia berdiri. Kontroversi itu sekaligus menunjukkan bahwa bukanlah gampang mencari logo berikut ornamen yang mampu memuaskan semua orang. Ini karena masing-masing individu memiliki selera estetis yang berbeda-beda.

Menjawab tantangan KeIndonesia-an sebagaimana telah dibedah di atas, pada hakikatnya, tidak bisa dipisahkan dengan nilai kemajemukan karena cara memandangnya yang luas, dan untuk menggapai keinginan untuk bersatu tersebut dibutuhkan satu ruang interaksi yang mampu menampung berbagai perbedaan latar belakang sosial. Sebagaimana diungkapkan Azra (2020), meski Indonesia kerap menghadapi situasi states of conflict-prone politics atau yang dapat diterjemahkan sebagai negara yang rentan dengan konflik politik, tapi ia pada prinsipnya tetaplah satu.

Hal ini setidaknya telah dibuktikan dengan gagalnya hipotesis yang dibangun Furnivall pada 1939. Dalam hipotesis yang disusun, Furnivall meramalkan terjadinya kiamat bagi Indonesia pasca era kolonial Belanda berakhir. Namun hingga lebih dari 70 tahun setelah ramalan tersebut disampaikan, hal tersebut tak kunjung terjadi. Kemajemukan memang di satu sisi menjadi identitas pembeda yang acapkali juga memicu konflik, tapi dalam konteks Indonesia ia agaknya menjadi sisi lain yang membuat kita terus berkomitmen untuk terus bertahan sebagai negara dan bangsa hingga hari ini. 

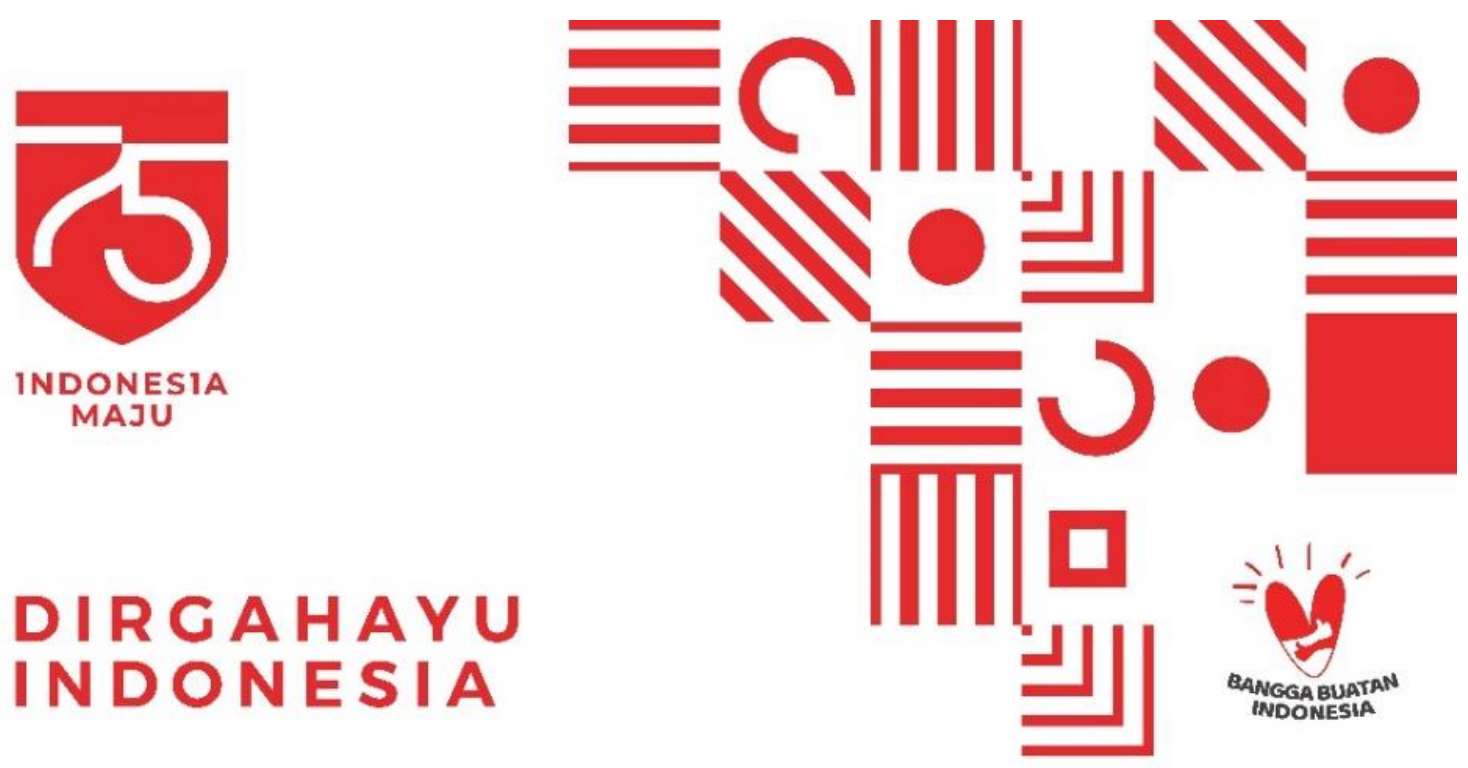

Gambar 1. Desain Ornamen 75 Tahun Kemerdekaan RI

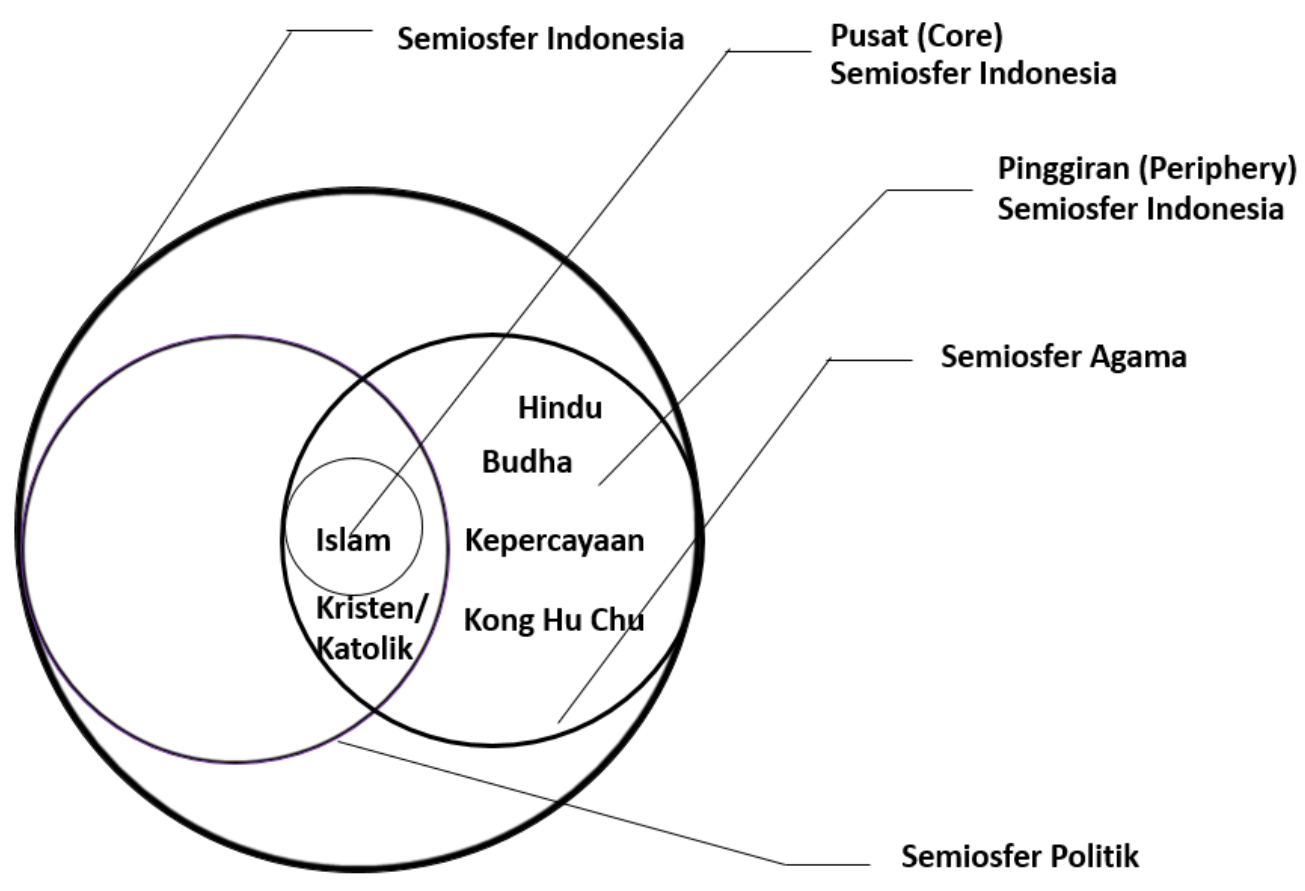

Gambar 2. Semiosfer Penelitian 


\section{KESIMPULAN}

Kajian ini menemukan bahwa penolakan terhadap ornamen "Salib" pada peringatan 75 tahun Kemerdekaan Indonesia pada dasarnya mencerminkan inner dan outer space. Pemaknaan itu menyangkut "kami" dan "mereka" yang dalam sejarah Indonesia telah berlangsung lama. Artinya, kontroversi mengenai simbol agama bukanlah hal baru.

Studi ini menyarankan bahwa dalam mengartikan sesuatu yang menyangkut seluruh elemen bangsa, sudah sepatutnya semua pihak menggunakan kacamata kemajemukan yang dijunjung para pendiri bangsa, bukan "inner space" masing-masing. Tulisan ini karenanya diharapkan dapat menjadi tambahan wawasan dalam memahami suatu tanda dan fenomena yang melingkupinya. Selain itu, otoritas yang telah diberi kewenangan untuk mengatur dan menegakkan aturan keamanan diwajibkan mampu untuk mengambil sikap tegas sesuai dengan koridor yang berlaku. Impunitas semper ad deteriora invitat, dimana hal ini dapat dimaknai bahwa pembiaran atas suatu peristiwa akan mengundang kejahatan lain yang memiliki skala lebih besar, apabila otoritas yang ada mengabaikan fakta serta penindakan lebih lanjut terhadap pelaku pelanggaran.

\section{DAFTAR PUSTAKA}

Azra, A. (2020). Indonesia Bertahan dari mendirikan negara hingga merayakan demokrasi. Penerbit Buku Kompas.

Britannica.com. 2018. Cross Religious Symbol. https://www.britannica.com/topic/c ross-religious-symbol

Cheregi, B. F. (2017). Nation Branding in Romania After 1989: A Cultural Semiotic Perspective. Romanian Journal of Communication and Public Relations, 19(1), 27. https://doi.org/10.21018/rjcpr.2017. 1.229

CNNIndonesia. (2020a). Agustus 10. Ormas di Solo Minta Pemerintah Revisi Logo HUT RI Mirip Salib. CNN Indonesia.

https://www.cnnindonesia.com/nasi onal/20200810203039-20534244/ormas-di-solo-mintapemerintah-revisi-logo-hut-ri-miripsalib
CNNIndonesia. (2020b). Eks Menag Respons Aa Gym soal Logo HUT RI Mirip Salib. CNN Indonesia. https://www.cnnindonesia.com/nasi onal/20200813112356-20535246/eks-menag-respons-aa-gymsoal-logo-hut-ri-mirip-salib

Gatra.com. (2020). Diprotes Ormas, Pemkab Hapus Ornamen Mirip Salib Logo HUT RI. Gatra.Com. https://www.gatra.com/detail/news/ 487105/gaya-hidup/diprotes-ormaspemkab-hapus-ornamen-mirip-saliblogo-hut-ri

Gunadha, Reza \& Bhayangkara, Chyntia Sami. 2020, Agustus 13. Logo HUT RI ke-75 Mirip Salib, Tengku Zul: Umat Mayoritas Mau Digilas? https://www.suara.com/news/2020/ 08/13/170936/logo-hut-ri-ke-75mirip-salib-tengku-zul-umatmayoritas-mau-digilas?page $=$ all 
Kompas. (2019). Api dalam Sekam Intoleransi Simbolik. Kompas. https://kompas.id/baca/utama/2019 /o1/o4/api-dalam-sekamintoleransi-simbolik/

Kull, K. (2015). A semiotic theory of life: Lotman's principles of the universe of the mind. Green Letters, 19, 1-12. https://doi.org/10.1080/14688417.2 015.1069203

Liputansumsel.com. (2020). Logo HUT RI Ke-75 Mirip Salib Umat Dan Ormas Islam Bereaksi. Liputansumsel.Com. https://www.liputansumsel.com/202 o/o8/logo-hut-ri-ke-75-mirip-salibumat-dan.html

Lorusso, A. M. (2015). Unity and Pluralism: The Theory of Jurij Lotman. Palgrave Macmillan.

Lotman, Y. (1990). Universe of The Mind: A Semiotic Theory of Culture. LB. Tauris \& Co Ltd.

Lotman, Y. (2005). On the Semiosphere. Sign Systems Studies.

Nariyati. (2020). Logo HUT RI diprotes gegara mirip salib, politikus hingga pengamat beri komentar. Hops.Id.

Nazaruddin, M. (2019). Tartu-Moscow Semiotic School and the Development of Semiotic Studies in Indonesia. Asian Journal of Media and Communication, 3(2).

Nöth, W. (2006). Yuri Lotman on Metaphors and Culture as Selfreferential Semiospheres. Semiotica, 1(4), 161.

Nöth, W. (2014). The Topography of Yuri Lotman's Semiosphere. International Journal of Cultural Studies.
Novikova, A. A., \& Chumakova, V. P. (2015). Yuri Lotman's Cultural Semiotics as a Contribution to Media Ecology. Explorations in Media Ecology, 14(1 \& 2).

Prijanto, J. H. (2017). Studi Terhadap Perang Salib Sebagai Upaya Penanaman Nilai-nilai Toleransi Dalam Pembelajaran Sejarah. Scholaria, 7(2), 118 - 125.

Sari, L. M. (2018). Simbol Salib Dalam Agama Kristen. Religi, 16(2), 155168.

Selvam, R. (2017). Is Jesus Death on the Cross a Satisfaction for the Sins of Humanity or a Demonstration of God's Love? A Theological Understanding of Atoneme in Relation to the Sacrament of Reconciliation. http://digitalcommons.lmu.edu/etd/ 318

Semenenko, A. (2012). The Texture of Culture An Introduction to Yuri Lotman's Semiotic Theory. Palgrave Macmillan.

Sugiharto, J. (2017). Kaleidoskop 2017: Pilkada Brutal Gubernur DKI Jakarta. Metro.Tempo.Co. https://metro.tempo.co/read/104510 3/kaleidoskop-2017-pilkada-brutalgubernur-dki-jakarta

Talia, S. (2018). Muslim Views of the Cross as a Symbol of the Christian Faith. Heirs of The Apostles.

Torop, P. (2005). Semiosphere and/as the research object of semiotics of culture. Sign Systems Studies. 
Jurnal komunikasi, Volume 15, Nomor 1, Oktober 2020, Hal 49-58 